\title{
Antecedents and Outcomes of Social Capital: Evidence from a Professional Baseball Franchise
}

\section{Yi-Hsiu Lin (D)}

Master Program of Sport Facility Management and Health Promotion, National Taiwan University, Taipei City, Taiwan, Republic of China
Correspondence: Yi-Hsiu Lin Emailshulin909@gmail.com
Purpose: The empirical paper aimed to develop a theoretical model of social capital in professional spectating sports by investigating the antecedents and outcomes related to social capital from the spectator's viewpoint.

Participant and Method: Brothers Elephants, a professional baseball franchise in the Chinese Professional Baseball League, provided the research setting. The study's participants consisted of 422 spectators of a Brothers Elephants game at its home field, Taichung Intercontinental Baseball Field. Around half of the participants were male; $46.4 \%$ of them aged between 30 and 39 years old. Data analysis was conducted through structural equation modeling.

Results: Results revealed that social interactions positively correlated with social capital, prosocial behavior, and spectator intention to re-attend the sporting event. Corporate social responsibility (CSR) also positively predicted intention to re-attend the sporting event, social capital, and prosocial behavior. Social capital significantly correlated with prosocial behavior and subjective well-being, and prosocial behavior significantly correlated with subjective well-being and intention to re-attend the sporting event.

Conclusion: The results suggest that social capital can be developed through social interactions and perceived CSR in the context of professional spectator sporting events, with such social capital increasing, in turn, prosocial behavior, subjective well-being, and intention to re-attend the sporting event. From perspective of practical implication, professional sports franchise can develop more campaigns that boost sports spectators' perceived social interactions and CSR, which can increase their social capital, prosocial behavior, subjective wellbeing, and their intention to re-attend the sporting event.

Keywords: sports event, prosocial behavior, subjective well-being, corporate social responsibility

\section{Introduction}

Sporting events create both economic and noneconomic benefits. Recently, researchers in sports management have begun investigating the social, rather than economic, effects of sport. ${ }^{1,2}$ Social effects include enhanced social value, civic pride, social cohesion, and social capital. ${ }^{3-5}$ Research regarding social effects has investigated both mega sporting events and community-based events. ${ }^{6-9}$ Studies have shown that social capital can be created and accumulated among sports participants, which generates camaraderie among individuals in the community. ${ }^{7,10}$ Because a growing consensus maintains that social capital can be developed through sports participation or attendance at sports events, ${ }^{6}$ it is a critical matter that warrants additional research.

Studies conducted qualitatively on social capital in the sports context have indicated that sport can bring social changes in the society. ${ }^{11,12}$ Sport has been 
demonstrated to create positive social changes. ${ }^{13}$ By hosting and taking part in sporting events, people can raise their social capital. ${ }^{8,9,14,15}$ Studies have argued that the benefits of participating in sport include the development of social capital, and one study created a sporting event participation social capital scale. ${ }^{16}$ Moreover, the literature has recommended that the difference between social capital and outcomes of social capital should be emphasized $^{17,18}$ because collectively participating in a community either formally or informally may not necessarily entail receipt of social capital. Social capital should be based on trust and reciprocity whereas outcomes of social capital should include the constructs or behaviors that result from social capital, ${ }^{16,19}$ which distinguishes social capital from outcomes of social capital. Although a number of studies have investigated social capital in the context of sport, exploring antecedents and outcomes of social capital in sport needs further investigation. ${ }^{16}$ Therefore, this study made theoretical and practical contributions by empirically constructing a theoretical model that incorporated the antecedents and outcomes of social capital in the context of professional sport.

\section{Conceptualization of Social Capital}

How studies have defined social capital has varied. ${ }^{20}$ Social capital is related to individuals in a community pursuing a common goal, ${ }^{21}$ and it can refer to the sense of connectedness between individuals. ${ }^{22}$ Additionally, Putnam ${ }^{18}$ suggested that social capital includes three characteristics: trust, a network, and reciprocity. Trust is deemed the most critical factor because a social network can only be established once trust is established. ${ }^{7}$ Putnam $^{20}$ further indicated that collective social engagement forms social ties, and Sherry ${ }^{10}$ argued that social capital is a multidimensional construct. Engagement in associational and civic interactions may be a means of creating networks and social norms related to social capital $^{23}$ that generate a high level of trust and reciprocity. This study defined social capital as a multidimensional construct in which the social ties of trust, networking, and reciprocity are evident among community members engaged in collective social engagement. Although scholars typically emphasize the positive benefits of social capital, negative outcomes, including racism, sectarianism, social exclusion, and corruption, are also associated with social capital. ${ }^{24}$ The current study, however, focused only on the positive benefits of social capital.

\section{Social Capital in Sport}

Social capital is applicable in the context of sport because sport facilitates the development of a community's internal relationships. ${ }^{25,26}$ Sport can also establish connections between communities and decrease one's sense of social isolation. ${ }^{8,27,28}$ The correlation between social capital and sport has been investigated, and although sport does not always increase social capital, ${ }^{8,10,17,28,29}$ sports management researchers have discovered that social capital can be generated through the organization of sport $^{3,7,14,30}$ or participation in sporting events. ${ }^{8,28}$ Sports participation has a positive effect on socially isolated individuals and is beneficial to the establishment of social relationships within a community. ${ }^{31}$

Social capital in sport can be roughly classified into three categories. First, sport create social benefits and achieve community goals through cooperation among stakeholders. ${ }^{13,14,17}$ Second, the literature has recognized that social capital between sports participants, volunteers, and coaches has can develop through sports participation..$^{9,10,15}$ Third, the effect of hosting mega sporting events on social capital, national identity, and social camaraderie has also been investigated. ${ }^{5,6,32,33}$

\section{Formation of Research Hypothesis in the Study \\ Social Interactions and Intention to Re-Attend the Sporting Event}

Social interactions in sporting events referred to connections among sports spectators. ${ }^{34} \mathrm{~A}$ refined definition of social interactions in sporting events proposed by KoenigLewis et $\mathrm{al}^{35}$ argued that temporary and enduring connections among sports spectators correspond, respectively, to interactions with anonymous others and familiar friends or family. Social interactions among sports spectators rather than the sporting event itself may be presumed to be a primary driver for value creation, ${ }^{35}$ which emphasized the importance of social interactions among sports spectators in sporting events.

Intention to re-attend the sporting event in this study is derived from behavioral intention. Behavioral intention in leisure and sports is often characterized by the intentions to recommend and revisit. ${ }^{36}$ More specifically, intention to recommend and revisit in this study refers to the intention to share the experience through word-of-mouth communications and return to the sporting event. As such, intention to re-attend the sporting event was conceptualized by 
adopting the notion that incorporated both intention to recommend and revisit as suggested by Inoue and Havard. $^{5}$

The theory of planned behavior argues that subjective norms are only one of the predictors of behavioral intention, ${ }^{37}$ suggesting that other factors also influence an individual's behavioral intention. In one study, most participants or spectators joined sports events with their significant others, implying that interacting with significant others during sports events strengthens people's intention to attend such events. ${ }^{38}$ Sports consumer behavior studies have argued that socialization is a primary motive for attending or participating in sports events. ${ }^{39,40}$ For example, participating in a running event can inspire psychological attachment through social interactions, and this can drive further participation in such events. ${ }^{16}$ Furthermore, facilitating interactions among sports spectators can enhance overall evaluations of the sporting event and subsequent word-of-mouth. ${ }^{35}$ Therefore, Hypothesis 1 (H1) postulated that perceived social interactions during the sporting event would positively correlate with the intention to re-attend the sporting event.

\section{Social Interactions and Social Capital}

An empirical study conducted at a running event determined that runners regarded community-based running events to be recreational events that provide a platform for social interactions with significant others. Therefore, running events may be a setting in which social capital is developed. ${ }^{16}$ More specifically, because social facilitation has been deemed a unique factor of sports events, ${ }^{39}$ participating in sporting events may be a means of interacting with peers and strengthening interpersonal connections or social networks. A similar concept can be applied to spectator sports events, and socialization is a reason that spectators attend such events. ${ }^{41}$ Additionally, social interactions were found to be correlated with social capital in the online game context. ${ }^{42}$ Thus, Hypothesis 2 (H2) claimed that spectators' perceived social interactions during the sporting events would positively correlate with their social capital.

\section{Social Interactions and Prosocial Behavior}

Prosocial behavior is defined as voluntary actions that can benefit other people in a way of physical helping, emotional comforting, and financial or social assistance. ${ }^{43,44}$ Sports participation promotes individuals' prosocial values and behavior. ${ }^{45}$ Similarly, an experimental design study indicated that sports consumers behavior is related to prosocial behavior. ${ }^{46}$

Social facilitation has been extensively exhibited in the context of sport, especially when sports fans are highly psychologically attached to a sports team. ${ }^{39}$ Fans who deeply identify with a specific team share an inclination to attend sporting events to both support the team and enjoy the game. The literature concerning group dynamics has argued that group identity contributes to an inclusive orientation among in-group members, ${ }^{47}$ and the in-group effect has a positive effect on prosocial team behavior in the context of sport. ${ }^{48,49}$ Additionally, social interactions resulting from attending a sporting event meet individuals' social needs. Thus, Hypothesis 3 (H3) proposed that spectators' perceived social interactions during the sporting event would be positively associated with their prosocial behavior.

\section{Corporate Social Responsibility (CSR) and Intention to Re-Attend the Sporting Event}

CSR refers to a series of activities adopted by an organization regarding its perceived societal obligations. ${ }^{50}$ Additionally, CSR is associated with an organization's ethical behavior and social obligations, which may be beyond the organization's financial goals. ${ }^{51} \mathrm{CSR}$ activities have been increasingly implemented in sports organizations to support various demands including economic, social and environmental causes required by the community. ${ }^{52}$

Empirical results revealed a positive indirect relationship between perceived corporate social responsibility and behavioral loyalty mediated by involvement ${ }^{53}$ and perception of social entrepreneurship. ${ }^{54}$ Individuals' perceptions toward CSR initiatives exerted an influence on the development of behavioral intention regarding spectator sports events. $^{55}$ Therefore, Hypothesis 4 (H4) postulated that spectators' perceived CSR during the sporting event would positively correlate with their intention to reattend the sporting event.

\section{CSR and Social Capital}

Philanthropical responsibility of CSR was demonstrated to have a positive influence on social capital. ${ }^{56}$ Sports events or sports organizations usually affiliate with specific philanthropic causes to increase participants' or spectators' psychological attachment and sense of meaningfulness. ${ }^{57-59}$ In addition, customers' perceived CSR generates connectedness with the corporations that 
engage in CSR. ${ }^{60}$ Therefore, Hypothesis 5 (H5) stated that spectators' perceived CSR during the sporting event would positively relate to their social capital.

\section{CSR and Prosocial Behavior}

Empirical studies have indicated that the perception of CRS has an effect on a group's prosocial behavior ${ }^{61}$ and encourages employees in the service industry to be prosocially motivated. ${ }^{62,63}$ Therefore, a person's persistent prosocial behavior can be improved through CSR involvement. ${ }^{64}$ Hypothesis 6 (H6) suggested that spectators' perceived CSR during the sporting event would positively relate to their prosocial behavior.

\section{Social Capital and Prosocial Behavior}

Social capital positively correlates with sports participation, such as participating in a sports and leisure club. ${ }^{65}$ The formation of social capital enables individuals to develop greater informal connections with other community members. ${ }^{66}$ Moreover, social capital may elicit prosocial behavior, including making donations to sports organizations that aid the community or serving in the community. ${ }^{16,66}$ Hypothesis 7 (H7), therefore, postulated that spectators' perceived social capital during the sporting event would positively correlate with their prosocial behavior.

\section{Social Capital and Subjective Well-Being}

Subjective well-being is defined as an individual's overall evaluation of their quality of life based on his or her life satisfaction, positive and negative emotions ${ }^{67,68}$ argued that subjective well-being is "an indicator of perceived long-term happiness, positive affect and life satisfaction" (p.2). Empirical studies indicated that subjective wellbeing is positively correlated with spectatorship in sporting events. ${ }^{69-71}$

Social capital has a positive correlation with subjective well-being. ${ }^{72,73}$ Similarly, one study found a positive relationship between social capital and subjective well-being in social media. ${ }^{74}$ Furthermore, two sub-dimensions of neighborhood connections as well as feelings of trust and safety were found to significantly mediate the association between sport participation and well-being. ${ }^{75}$ Hence, Hypothesis 8 (H8) postulated that spectators' perceived social capital would positively relate to their subjective well-being.

\section{Prosocial Behavior and Subjective Well-Being}

Prosocial behavior positively correlates with gratitude, ${ }^{76}$ which in turn exerts a positive influence on subjective well-being. ${ }^{77}$ Subjective well-being positively correlates with prosocial behavior, ${ }^{78}$ and an online study suggested that altruistic behavior positively correlates with subjective well-being. ${ }^{79}$ Additionally, positive feelings are a significant outcome variable of prosocial behavior. ${ }^{80}$ Hypothesis 9 (H9), therefore, suggested that specatators' perceived prosocial behavior would positively relate to their subjective well-being.

\section{Prosocial Behavior and Intention to Re-Attend the Sporting Event}

A key outcome of prosocial behavior is individuals' contributions to a group. ${ }^{81}$ Attending sporting events attracts companions and significant others to participate because of the social opportunities provided during spectating sports. Additionally, a friend's behavior is associated with an individual's prosocial goal pursuit. ${ }^{82}$ Attending sports events with friends or significant others may be a method of contributing to the group that includes the significant others. Hypothesis 10 (H10) postulated that spectators' perceived prosocial behavior would positively relate to their intention to re-attend the sporting event.

\section{Materials and Methods Research Setting}

Brothers Elephants, a franchise in the Chinese Professional Baseball League (CPBL), was the research setting of this study. The home field of Brothers Elephants is located in Taichung City. Brothers Elephants has been playing in the CPBL since its establishment in 1990 and has gained popularity and a large fan base in Taiwan. The average number of spectators per game for CPBL and Brother Elephants was 3573 and 4086 in 2020 season, respectively, ${ }^{83}$ which implies that Brother Elephants has been popular among fans in CPBL.

\section{Research Design and Procedure}

The study was to develop a theoretical model of social capital in professional spectating sports by investigating the antecedents and outcomes related to social capital. As such, a cross-sectional research design was adopted. A self-administered online survey was applied for data collection.

The research procedure in the study consists of several parts. After the theme of the study was confirmed, an extensive review of literature was performed. Research hypotheses were rigorously developed then. Next, an online survey was generated. Additionally, on-site data 
collection was conducted after research ethics application was approved. Finally, solid data analyses was performed and insightful findings were reported.

\section{Participants}

Brothers Elephants, a professional baseball franchise in the CPBL provided the research setting. The Research Ethics Committee (REC) of National Taiwan University (NTU) has reviewed and approved this study. This study followed the code of ethics required by REC at NTU and was conducted in accordance with the Declaration of Helsinki. A group of seven research assistants collected data through stratified sampling at a Brothers Elephants home game at Taichung Intercontinental Baseball Field during the $2020 \mathrm{CPBL}$ season. More specifically, the data collection was conducted on November 1, 2020. The inclusion criterion for participants was being a spectator 20 years of age and older. The exclusion criterion for participants was being a spectator who was unable to communicate in Chinese. After having been assigned to specific zones in the ballpark, the research assistants approached spectators and asked if they were willing to participate in this study. Interested spectators were given a QR code that linked to the online questionnaire. The online survey started with informed consent to participate in the study. After reviewing the content of informed consent, participants can either proceed to the questionnaire by clicking "I completely understand and agree with the content of informed consent" or simply exit the survey if they were not willing to participate. Specifically, informed consent from the participants in the study were well obtained prior to study commencement. Giveaways of Brothers Elephants licensed merchandise served to incentivize participants to complete the survey. Participants spent approximately 5 to 10 minutes completing the survey, and 422 valid responses were collected. The sampling error of the study was estimated to be $2.8 \%$ based on the conditions (sample size of 422 , average number of spectators per Brother Elephants' game of 4086 and confidence interval of 95\%). Among the participants, $50.5 \%$ were male; $49.5 \%$ were female. The age distribution of participants were $29.9 \%$ (20-29), 46.4\% (30-39), $21.3 \%$ (40-49), and 2.4\% (50 and above). The profile of participants' education was $7.8 \%$ (senior high school and below), $69.9 \%$ (bachelor), $21.6 \%$ (master), and $0.7 \%$ (doctorate). Finally, the information of participants' occupation was $1.2 \%$ (farming), $17.8 \%$ (military/civil servants/ education), 34.8\% (services), 13.3\% (manufacturing), $11.1 \%$ (business), and $21.8 \%$ (others).

\section{Measurement}

The scales measuring social capital were adopted from the work of Gibson et $\mathrm{al}^{6}$ and included five subdimensions: collective action, trust and safety, social connections, tolerance of diversity, and value of life. Social interactions were measured using the scale developed by Funk et al. ${ }^{41}$ Two items from the original survey, "If someone's car breaks down outside my house, I will invite them in to use the phone" and "In the past 6 months, I have done a favor for a sick neighbor" were removed because of insufficient suitability for the Taiwanese context. Because social capital is society specific, adapting the instrument for valid measurement is reasonable. ${ }^{84} \mathrm{CSR}$ was measured using the scale adapted from Lichtenstein et al. ${ }^{85}$ Subjective well-being was measured using the scale developed by Portela et al. ${ }^{73}$ Intention to re-attend the sporting event was measured from the work of Inoue and Havard, ${ }^{5}$ and prosocial behavior was measured using the scale developed by Baumsteiger and Siegel. ${ }^{86}$ All criteria were measured by means of a 7-point Likert scale with 1 referring to "strongly disagree" and 7 denoting "strongly agree" (Table 1). Finally, demographic variables, including gender, age, educational background, and occupation, were collected.

The construct validity of the measurements in the study was ensured through confirmatory factor analysis (CFA). An acceptable level of model fit was indicated for this study. The average variance extracted (AVE) for all constructs in the study exceeded 0.5. Meanwhile, the standardized factor loadings of all items were greater than 0.5 , indicating that acceptable convergent validity was attained (Table 1). Moreover, the AVEs for each construct exceeded the shared variance between constructs, indicating that discriminant validity of the measurements was achieved (Table 2). The Cronbach's alpha and composite reliability for all constructs in this study ranged from 0.81 to 0.90 and from 0.77 to 0.92 , demonstrating satisfactory reliability. Additionally, normal distribution of data was implied as the absolute value of skewness and kurtosis of all variables was less than 3 and 10 , respectively. ${ }^{87}$

In addition to avoiding item ambiguity by adopting a valid and reliable measurement scale, Harman's single factor test was performed to examine common method variance. Specifically, the results of the Kaiser-MeyerOlkin test $(0.91)$ and Bartlett's test of sphericity $\left(\chi^{2}=\right.$ 5818.03 , d.f. $=171, p<0.01)$ revealed that the sample 
Table I Summary of Confirmatory Factor Analysis

\begin{tabular}{|c|c|c|c|c|c|c|}
\hline Construct/Item & $\mathbf{M}$ & SD & SK & KU & $\lambda$ & $\mathbf{t}$ \\
\hline Social Capital- Collective Action & 4.51 & 1.81 & -0.25 & -1.03 & 0.68 & - \\
\hline I regularly attend local community events. & 5.11 & 1.85 & -0.78 & -0.45 & & \\
\hline I help out a local group as a volunteer. & 4.42 & 2.05 & -0.25 & -1.26 & & \\
\hline I participate on management or organizing committees for local organizations. & 4.39 & 2.08 & -0.29 & -1.22 & & \\
\hline I participate in any local community action groups that deal with emergencies. & 4.21 & 2.06 & -0.15 & -1.24 & & \\
\hline I take part in local community projects. & 4.41 & 2.20 & -0.28 & -1.13 & & \\
\hline Social Capital-Trust and Safety & 5.41 & 1.09 & -0.36 & -0.12 & 0.83 & 14.97 \\
\hline My local area have a reputation for being a safe place. & 5.98 & 1.13 & -1.35 & 2.10 & & \\
\hline I feel safe walking down your street after dark. & 5.62 & 1.37 & -1.01 & 0.47 & & \\
\hline I agree that most people can be trusted. & 5.66 & 1.26 & -1.09 & 1.27 & & \\
\hline My local community feel like home. & 4.38 & 1.85 & -0.04 & -1.21 & & \\
\hline Social Capital- Social Connections & 4.90 & 1.36 & -0.05 & -0.82 & 0.80 & 14.47 \\
\hline I have visited a neighbor in the past week. & 5.49 & 1.29 & -0.66 & 0.05 & & \\
\hline I can get help from friends when I need it & 4.60 & 2.02 & -0.39 & -1.12 & & \\
\hline I feel safe walking down your street after dark & 5.52 & 1.37 & -0.91 & 0.32 & & \\
\hline In the past week, I agree that I have had many phone conversations with friends. & 4.00 & 2.07 & -0.02 & -1.26 & & \\
\hline Social Capital- Tolerance of Diversity & 5.49 & 1.19 & -0.51 & -0.11 & 0.72 & 13.23 \\
\hline I enjoy living among people of different lifestyles. & 5.15 & $1.5 \mathrm{I}$ & -0.55 & -0.26 & & \\
\hline I think that multiculturalism would make life in my area better & 5.65 & 1.24 & -0.76 & 0.26 & & \\
\hline If someone different moved to my street, they would be accepted by the neighbors. & 5.67 & 1.29 & -0.96 & 0.65 & & \\
\hline Social Capital-Value of Life & 5.50 & 1.09 & -0.27 & -0.66 & 0.81 & $|4.6|$ \\
\hline I value the society in which I live & 5.83 & 1.35 & -1.10 & 1.18 & & \\
\hline I feel valued by society. & 5.46 & 1.26 & -0.65 & 0.40 & & \\
\hline If I were to die tomorrow, I would be satisfied with your life. & 5.22 & 1.52 & -0.80 & 0.22 & & \\
\hline \multicolumn{7}{|l|}{ Social Interactions } \\
\hline I like to talk with other people sitting near me at the Brother Elephants games. & 6.06 & 1.09 & -1.34 & 1.69 & 0.85 & - \\
\hline The Brother Elephants games give me a great opportunity to socialize with other people. & 5.99 & 1.15 & -1.52 & 2.88 & 0.92 & 23.06 \\
\hline I attend Brother Elephants games because of the opportunities to socialize. & 5.67 & 1.45 & -1.19 & 1.14 & 0.71 & 16.38 \\
\hline \multicolumn{7}{|l|}{ Corporate Social Responsibility } \\
\hline Brothers Elephants have been dedicated to local community development. & 5.87 & 1.32 & -1.32 & 1.61 & 0.93 & - \\
\hline Brothers Elephants give back to the communities in which it does business. & 5.97 & 1.25 & -1.40 & 2.11 & 0.92 & 30.90 \\
\hline Local communities benefit from Brothers Elephants' contributions. & 6.09 & 1.15 & -1.74 & 4.19 & 0.81 & 23.71 \\
\hline
\end{tabular}

(Continued) 
Table I (Continued).

\begin{tabular}{|c|c|c|c|c|c|c|}
\hline Construct/Item & M & SD & SK & KU & $\lambda$ & $\mathbf{t}$ \\
\hline \multicolumn{7}{|l|}{ Subjective Wellbeing } \\
\hline Taking all things together, I am happy. & 5.92 & 1.12 & -1.26 & 2.11 & 0.86 & - \\
\hline All things considered, I am satisfied with my life as a whole nowadays. & 5.77 & 1.30 & -1.32 & 1.87 & 0.80 & 16.05 \\
\hline \multicolumn{7}{|l|}{ Intention to Re-attend the sporting event } \\
\hline Attend the Brothers Elephants games next season & 6.32 & 1.09 & -2.05 & 4.81 & 0.89 & - \\
\hline Recommend the Brothers Elephants games to others & 6.37 & 0.96 & -1.90 & 4.36 & 0.88 & 24.72 \\
\hline Say positive things about the Brothers Elephants games & 6.27 & 1.09 & -1.82 & 3.61 & 0.85 & 22.98 \\
\hline \multicolumn{7}{|l|}{ Prosocial Behavior } \\
\hline Comfort someone I know after they experience a hardship & 5.91 & 1.17 & $-|.3|$ & 2.01 & 0.75 & - \\
\hline Help a stranger find something they lost, like their key or a pet & 6.27 & 0.89 & -1.22 & 1.20 & 0.77 & 14.60 \\
\hline Help care for a sick friend or relative & 5.99 & 1.19 & -1.55 & 2.93 & 0.67 & 12.87 \\
\hline
\end{tabular}

Notes: $\chi^{2}=533.1 \mathrm{I}, \mathrm{df}=137, \chi^{2} / \mathrm{df}=3.89$, RMSEA $=0.088,90 \% \mathrm{Cl}$ for RMSEA $=(0.08 \mathrm{I}, 0.095), \mathrm{NFI}=0.96, \mathrm{CFI}=0.97, \mathrm{SRMR}=0.054$. Adapted with permission from Gibson $\mathrm{HJ}$, Walker M, Thapa B, et al. Psychic income and social 630capital among host nation residents: a pre-post analysis of the 20IOFIFA World Cup in South Africa. Tour Manage. 2014;(44):1 13-122. Copyright Elsevier 2014. ${ }^{6}$

Abbreviations: M, Mean; SD, Standard Deviation, SK, Skewness; KU, Kurtosis; $\lambda$, Standardized Factor Loading.

was adequate for factor analysis. The result of factor analysis suggests that the first factor explained $47.33 \%$ of the total variance. Accordingly, common method variance was avoided in this study.

\section{Data Analysis}

The statistical methods used in this study were descriptive statistics, internal consistency coefficient, composite reliability, Harman's single factor test, CFA, and structural equation modeling (SEM), all of which were performed in SPSS 20.0 and LISREL 8.70. The mean, standard deviation, skewness, and kurtosis were computed for descriptive statistics. The internal consistency coefficient was computed to examine reliability using the criterion proposed by Nunnally and Bernstein. ${ }^{88}$ Moreover, Harman's single factor test was performed to investigate the issue of common method bias. ${ }^{89}$ Item parceling was applied to the scale of social capital and generated the average scores of its five subdimensions. These served as the indicator scores in subsequent data analysis, including CFA and SEM. CFA was conducted to examine construct validity, ${ }^{90}$ including convergent validity and discriminant validity, as proposed by Hair et al. ${ }^{91}$ Finally, SEM was performed to investigate the proposed structural relationships in this study. Covariance matrix as inputs along with maximum likelihood estimation was applied when performing CFA and SEM in the study.

\section{Results}

Ten research hypotheses (H1 through H10) were proposed and tested to empirically explore antecedents and outcome variables associated with social capital in professional spectating sports from the spectator's perspective. According to the criteria suggested by Hair et al. ${ }^{73}$ SEM results provided a satisfactory measure of the data: $\chi^{2} /$ d.f. $=4.22\left(\chi^{2}=596.28\right.$, d.f. $=141), \mathrm{NFI}=0.96, \mathrm{CFI}=0.97, \mathrm{SRMR}=0.063$, RMSEA $=0.095,90 \%$ CI for RMSEA $=(0.088,0.010)$. All proposed hypotheses in the present study were supported (Figure 1).

$\mathrm{H} 1, \mathrm{H} 2$, and $\mathrm{H} 3$ postulated positive correlations between spectators' perceived social interactions during the sporting event and intention to re-attend the sporting event, social capital, and prosocial behavior. Analysis indicated that all paths were statistically significant $\left(\gamma_{\mathrm{H} 1}=0.20, \mathrm{t}=3.02 ; \gamma_{\mathrm{H} 2}=\right.$ $\left.0.54, t=7.34 ; \gamma_{\mathrm{H} 3}=0.30, t=4.08\right)$; thus, $\mathrm{H} 1$ through $\mathrm{H} 3$ were supported. Results implied that the higher the degree of sports spectators' perceived social interaction was in the sporting event, the higher their intention to return, perceived social capital, and prosocial behavior were.

$\mathrm{H} 4, \mathrm{H} 5$, and $\mathrm{H} 6$ proposed positive correlations between spectators' perceived CSR and their intention to re-attend the sporting event, social capital, and prosocial behavior. Analysis demonstrated that all associations between spectators' perceived CSR and their intention to re-attend the sporting 
Table 2 Correlation, Shared Variance, and Average Variance Extracted

\begin{tabular}{|l|c|c|c|c|c|c|c|c|c|c|}
\hline & M & SD & $\alpha$ & CR & SWB & IR & PSB & SC & SI & CSR \\
\hline SWB & 5.85 & 1.11 & 0.81 & 0.82 & 0.69 & 0.28 & 0.49 & 0.36 & 0.34 & 0.45 \\
IR & 6.32 & 0.96 & 0.90 & 0.91 & 0.53 & 0.76 & 0.53 & 0.13 & 0.42 & 0.40 \\
PSB & 6.05 & 0.90 & 0.81 & 0.77 & 0.70 & 0.73 & 0.53 & 0.40 & 0.45 & 0.37 \\
SC & 5.16 & 1.09 & 0.84 & 0.88 & 0.60 & 0.36 & 0.63 & 0.59 & 0.40 & 0.24 \\
SI & 5.90 & 1.08 & 0.84 & 0.87 & 0.58 & 0.65 & 0.67 & 0.63 & 0.69 & 0.46 \\
CSR & 5.98 & 1.15 & 0.87 & 0.92 & 0.67 & 0.63 & 0.61 & 0.49 & 0.68 & 0.79 \\
\hline
\end{tabular}

Notes: Average variance extracted, correlation and shared variance are presented in the diagonal, lower- and upper-triangle, respectively. M, SD, $\alpha$ and CR refer to mean, standard deviation, Cronbach's internal consistency coefficient, composite reliability, respectively.

Abbreviations: SI, Social Interactions; IR, Intention to Re-attend the sporting event; SC, Social Capital; PSB, Prosocial Behavior; CSR, Corporate Social Responsibility; SWB, Subjective Well-being.

event, social capital, and prosocial behavior were statistically $\operatorname{significant}\left(\gamma_{\mathrm{H} 4}=0.20, \mathrm{t}=3.28 ; \gamma_{\mathrm{H} 5}=0.14, t=2.11 ; \gamma_{\mathrm{H} 6}=0.33\right.$, $t=5.19)$. Therefore, $\mathrm{H} 4, \mathrm{H} 5$, and $\mathrm{H} 6$ were supported. Findings suggested that the more favorable attitudes toward CSR adopted by sports franchises, the greater their intention to reattend the sporting event, social capital, and prosocial behavior were.

H7 explored the relationship between spectators' social capital and their prosocial behavior and H8 focused on the relationship between spectators' social capital and their subjective well-being. Analysis revealed that the relationships between spectators' social capital and their prosocial behavior was statistically significant $\left(\beta_{\mathrm{H} 7}=0.24, t=3.80\right)$; spectators' social capital and their subjective well-being was statistically significant $\left(\beta_{\mathrm{H} 8}=0.27, t=4.32\right)$. Therefore, $\mathrm{H} 7$ and $\mathrm{H} 8$ were supported. Results indicated that the higher the degree of sports spectators' perceived social capital, the higher perceived prosocial behavior and subjective well-being were.

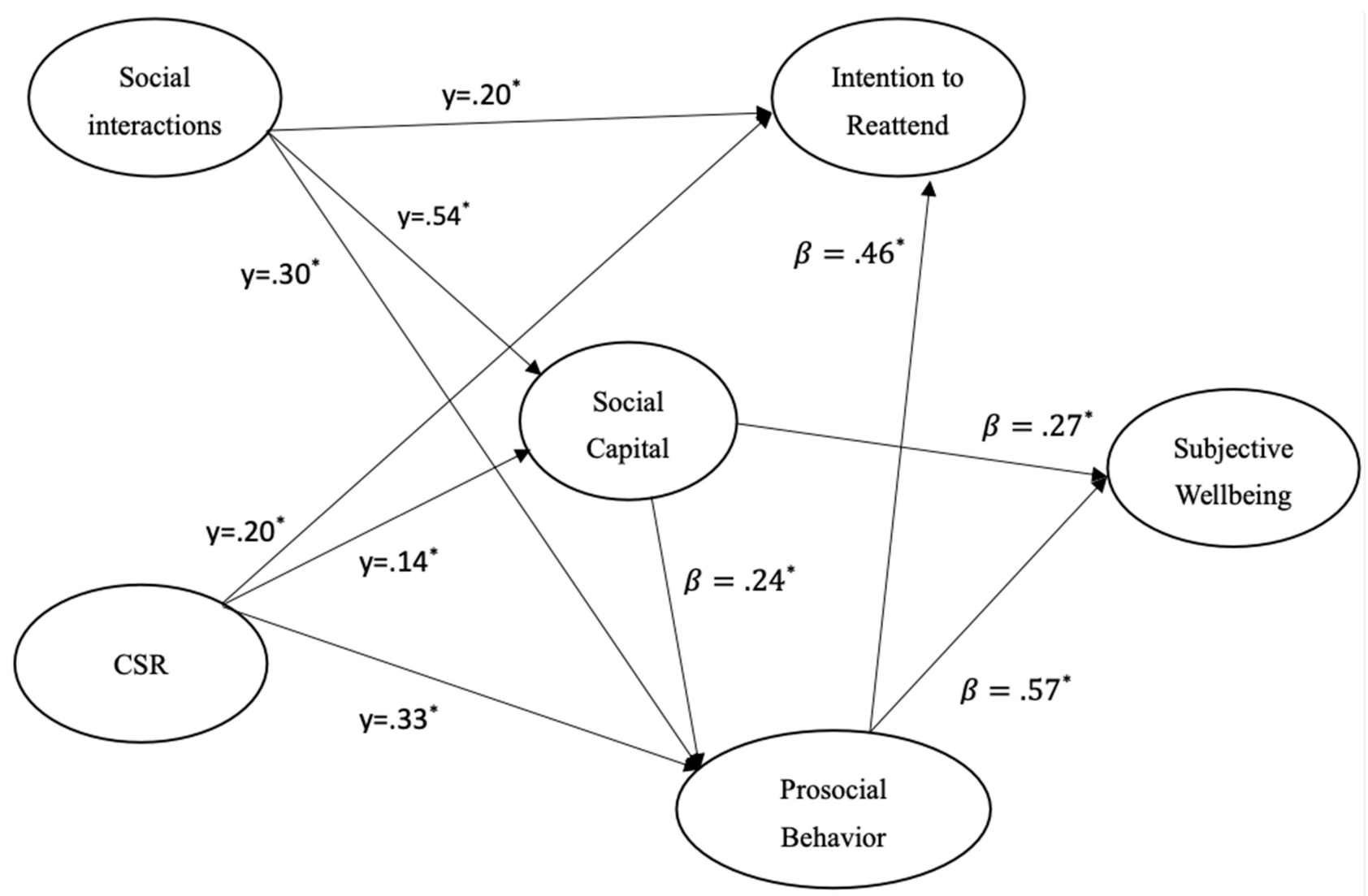

Figure I The Structural Model in the Study. ${ }^{*} \mathrm{p}<0.05 . \chi^{2}=596.28, \mathrm{df}=\mid 4 \mathrm{I}, \chi^{2} / \mathrm{df}=4.22, \mathrm{RMSEA}=0.095,90 \% \mathrm{Cl}$ for $\mathrm{RMSEA}=(0.088,0.10), \mathrm{NFI}=0.96, \mathrm{CFI}=0.97, \mathrm{SRMR}=0.063$. 
H9 examined the relationship between spectators' prosocial behavior and their subjective well-being, and H10 investigated the relationship between spectators' prosocial behavior and their intention to re-attend the sporting event. Because analysis indicated that spectators' prosocial behavior significantly predicted their subjective well-being $\left(\beta_{\mathrm{H} 9}=0.57, t=8.24\right)$, and intention to re-attend the sporting event $\left(\beta_{\mathrm{H} 10}=0.46, t=6.23\right)$, meaning that $\mathrm{H} 9$ and H10 were supported. Results suggested that the higher the degree of sports spectators' prosocial behavior, the higher subjective well-being and intention to re-attend the sporting event were.

\section{Discussion}

Results of this study demonstrated that several antecedents and outcome variables associated with social capital generate positive social interactions among participants in professional sporting events. Social interactions positively predicted intention to re-attend the sporting event (H1), which is consistent with Azjen's theory of planned behavior ${ }^{37}$ that emphasizes the influence of significant others on behavioral intention. Socialization and social facilitation have been considered to be primary motives for attending sporting events, ${ }^{38-40}$ which supports the finding that social interactions positively correlate with intention to re-attend sporting events, and echoes that social interactions enhance sports spectators' loyalty to the sporting events. ${ }^{35}$ Furthermore, social interactions positively predicted social capital (H2), which is consistent with the finding from empirical studies that participation in sports can be conducive to the development of social capital. ${ }^{16}$ Similarly, such findings echo the positive correlation between social interactions and social capital in the online game context. ${ }^{42}$ Additionally, social interactions positively predicted prosocial behavior (H3). Social interactions during the sporting event may be an element of group identity that leads to a sense of inclusiveness among in-group members, ${ }^{47}$ which then positively affects prosocial behavior in sport. ${ }^{48,49}$ Accordingly, professional sports franchises may consider developing promotional activities to enhance spectators' perceived social interactions in the ballpark, which can increase their intention to re-attend to the sporting event, prosocial behavior, and social capital.

CSR positively predicted intention to re-attend the sporting event (H4). The finding is consistent with empirical results from the literature, ${ }^{53,55}$ suggesting greater perceived CSR directly or indirectly leads to greater intention to reattend the sporting event. Moreover, CSR was found to positively affect social capital (H5), which is consistent with the literature. ${ }^{57-59}$ Furthermore, perceived CSR positively related to prosocial behavior (H6), which is consistent with the empirical findings that CSR perceptions lead to or improve prosocial behavior. ${ }^{61-64}$ As such, effectively communicating with spectators on the CSR initiatives and campaigns engaged by professional sports franchises becomes critical in order to ensure greater intention to re-attend the sporting event, social capital and prosocial behavior.

Social capital also predicted positive prosocial behavior (H7), which is consistent with empirical findings. ${ }^{16,66}$ Higher perceived social capital leads to a higher level of prosocial behavior. Additionally, social capital predicted positive subjective well-being (H8). This finding is consistent with those from empirical research that perceived social capital positively correlated with subjective wellbeing, ${ }^{72,73}$ specifically in the contexts of family and social media (Hwang et al, 2019). ${ }^{63,74}$ Wise utilization of social media by professional sports franchises on building up perceived social capital among spectators is encouraged.

Prosocial behavior was positively associated with subjective well-being (H9), which is consistent with empirical findings from the literature that prosocial or altruistic behavior positively correlates with subjective well-being. ${ }^{78,79}$ Additionally, perceived prosocial behavior in sports events positively relates to intention to re-attend the sporting event (H10). This finding is echoed in the literature, such as in the works of Batson and Powell ${ }^{81}$ and Barry and Wentzel, ${ }^{82}$ who found that individuals contribute to the group by attending sporting events with their significant others. Constant communications with spectators on what professional sports franchises have dedicated to in terms of prosocial behavior in the ballpark is encouraged, such as displaying signage that signals sports-related prosocial behavior.

Some limitations of the current study must be addressed. First, the antecedents and outcomes associated with social capital in the study may not be comprehensive. Accordingly, future studies should incorporate different potential variables that cause and are caused by social capital in the context of professional spectator sports. Moreover, the study was conducted in the context of professional baseball, which may not lend the findings sufficient generalizability. Therefore, further efforts are encouraged to investigate the proposed model within the context of various sports and cultures. Additionally, various measurement instruments regarding the variables under study can be found in literature. Future studies may consider adopting different measurement instruments to validate the findings from this study. Finally, the representativeness of the sample in the study may not be satisfactorily 
ensured due to the limited information concerning target population profile of Brother Elephants' spectators. As such, multiple samples and multiple study designs are encouraged for future investigations.

\section{Conclusion}

The current study yielded contributions to the literature on social capital in professional spectator sports theoretically and practically. First, the present study responded to calls to thoroughly explore antecedents and outcome variables associated with social capital in the context of sports by constructing a theoretical model. ${ }^{16}$ Second, the perceived social interactions and CSR were found to contribute to the formation of social capital, prosocial behavior, and intention to return to another sporting event. Third, social capital was determined to promote subjective well-being and prosocial behavior. Fourth, prosocial behavior was determined to promote subjective well-being and intention to return to another sporting event. Finally, the results from the present study indicated that social capital can be developed by attending or participating in sports events through social interactions and CSR, which generate a greater level of prosocial behavior, subjective well-being, and intention to return. From perspective of practical implication, professional sports franchise can develop more campaigns that boost sports spectators' perceived social interactions and CSR, which can increase their social capital, prosocial behavior, subjective well-being, and their intention to re-attend the sporting event. Professional spectator sport events, therefore, can be beneficial for not only the sports franchise but also society as a whole. To elaborate, sports franchises may benefit from spectators' greater intention to re-attend the sporting events. In the meantime, the society as a whole may benefit from spectators' increased social capital, prosocial behavior and subjective well-being.

\section{Acknowledgments}

The study was funded by Ministry of Science and Technology, Republic of China. MOST 109-2635H-002-001.

\section{Disclosure}

The author reports no conflicts of interest in this work.

\section{References}

1. Yamashita R. Mega-para-sporting event social impacts perceived by Tokyo residents: comparison of residents' vitality. Sustainability. 2021;13(16):9311. doi:10.3390/su13169311

2. Cardella GM, Hernandez-Sanchez BR, Sanchez-Garcia JC. Entrepreneurship and sport: a strategy for social inclusion and change. Int $J$ Environ Res Public Health. 2021;18(9):4720. doi:10.3390/ijerph18094720

3. Gibson HJ, Willming C, Holdnak A. Small-scale event sport tourism: fans as tourists. Tour Manag. 2003;24(2):181-190. doi:10.1016/ S0261-5177(02)00058-4

4. Gibson HJ, Kaplanidou K, Kang SJ. Small-scale event sport tourism: a case study in sustainable tourism. Sport Manag Rev. 2012;15 (2):160-170. doi:10.1016/j.smr.2011.08.013

5. Inoue Y, Havard C. Determinants and consequences of the perceived social impact of a sport event. J Sport Manag. 2014;28(3):294-310. doi:10.1123/jsm.2013-0136

6. Gibson HJ, Walker M, Thapa B, et al.Psychic income and social capital among host nation residents: a pre-post analysis of the 2010 FIFA World Cup in South Africa. Tour Manage. 2014;(44):113-122. doi:10.1016/j.tourman.2013.12.013

7. Schulenkorf N, Thomson A, Schlenker K. Intercommunity sport events: vehicles and catalysts for social capital in divided societies. Event Manag. 2011;15(2):105-119. doi:10.3727/152599511X13082349958316

8. Sherry E. (Re)engaging marginalized groups through sport: the Homeless World Cup. Int Rev Sociol Sport. 2010;45(1):59-71. doi: $10.1177 / 1012690209356988$

9. Welty Peachey J, Cohen A, Borland J, et al. Building social capital: examining the impact of Street Soccer USA on its volunteers. Int Rev Sociol Sport. 2013;48(1):20-37.

10. Sherry E, Karg A, O’May F. Social capital and sport events: spectator attitudinal change and the Homeless World Cup. Sport Soc. 2011;14 (1):111-125. doi:10.1080/17430437.2011.530015

11. Czekanski WA, Lower-Hoppe LM, Marsh P, Peterson J. Partnerships in collegiate sport clubs: a social exchange perspective. Eur Sport Manag Q. 2021. doi:10.1080/16184742.2021.1952467

12. Richmond A, de Leeuw E, Bunde-Birouste A. Towards negotiation: a RAMESES narrative review of social enterprise to support sustainability in Sport for Social Change (S4SC). Nonprofit Manag Leadersh. 2021. doi:10.1002/nml.21488

13. Skinner J, Zakus DH, Cowell J. Development through sport: building social capital in disadvantaged communities. Sport Manag Rev. 2008;11(3):253-275. doi:10.1016/S1441-3523(08)70112-8

14. Misener L, Mason DS. Creating community networks: can sporting events offer meaningful sources of social capital? Manag Leis. 2006;11(1):39-56.

15. Welty Peachey J, Borland J, Lobpries J, et al. Managing impact: leveraging sacred spaces and community celebration to maximize social capital at a sport-for-development event. Sport Manag Rev. 2015;18(1):86-98. doi:10.1016/j.smr.2014.05.003

16. Zhou R, Kaplanidou K, Wegner C. Social capital from sport event participation: scale development and validation. Leis Stud. 2021;40:612-627. doi:10.1080/02614367.2021.1916832

17. Tonts M. Competitive sport and social capital in rural Australia. $J$ Rural Stud. 2005;21(2):137-149. doi:10.1016/j.jrurstud.2005.03.001

18. Narayan D, Cassidy M. A dimensional approach to measuring social capital: development and validation of a social capital inventory. Curr Sociol. 2001;49(2):59-102. doi:10.1177/0011392101049002006

19. Putnam R. Bowling alone: america's declining social capital. J Democr. 1995;6:65-78. doi:10.1353/jod.1995.0002

20. Putnam R. Bowling Alone: The Collapse and Revival of American Community. Simon and Schuster; 2001.

21. DeGraaf D, Jordan D. Social capital: how parks and recreation help to build community. Parks Rec. 2003;7:21-27. 
22. Bourdieu P. Distinction: A Social Critique of the Judgement of Taste. London: RKP; 1984.

23. Mohan G, Mohan J. Placing social capital. Prog Hum Geogr. 2002;26 (2):191-210. doi:10.1191/0309132502ph364ra

24. Uribe CA. The dark side of social capital re-examined from a policy analysis perspective: networks of trust and corruption. J Comp Policy Anal. 2014;16(2):175-189.

25. Sherry E, Karg A, O'May F. Social capital and sport events: spectator attitudinal change and the Homeless World Cup. Sport Soc. 2011;14 (1):111-125.

26. Smith A, Westerbeek H. Sport as a vehicle for deploying corporate social responsibility. J Corp Citizen. 2007;25:43-54.

27. Burnett C. Building social capital through an active community club. Int Rev Sociol Sport. 2006;41(3-4):283-294. doi:10.1177/ 1012690207078381

28. Spaaij R. Sport as a vehicle for social mobility and regulation of disadvantaged urban youth. Int Rev Sociol Sport. 2009;44(23):247-264. doi:10.1177/1012690209338415

29. Smith JM, Ingham AG. On the waterfront: retrospectives on the relationship between sport and communities. Sociol Sport J. 2003;20(3):252-274. doi:10.1123/ssj.20.3.252

30. Chalip L. Towards social leverage of sport events. J Sport Tour. 2006;11(2):109-127. doi:10.1080/14775080601155126

31. Collins M, Kay T. Sport and Social Exclusion. London: Routledge; 2003.

32. Heere B, Walker M, Gibson $\mathrm{H}$, et al. Ethic identity over national identity: an alternative approach to measure the effect of the World Cup on social cohesion. $J$ Sport Tour. 2016;20(1):41-56. doi:10.1080/14775085.2016.1175369

33. Mackellar J, Jamieson N. Assessing the contribution of a major cycle race to host communities in South Australia. Leis Stud. 2015;34 (5):547-565. doi:10.1080/02614367.2014.938772

34. Wann D. Understanding the positive social psychological benefits of sport team identification: the team identification-social psychological health model. Group Dyn Theory Res Pract. 2006;10(4):272-296. doi:10.1037/1089-2699.10.4.272

35. Koenig-Lewis N, Asaad Y, Palmer A. Sports events and interaction among spectators: examining antecedents of spectators' value creation. Eur Sport Manag Q. 2018;18(2):193-215. doi:10.1080/ 16184742.2017.1361459

36. Jeong Y, Yu A, Kim SK. The antecedents of tourists' behavioral intentions at sporting events: the case of South Korea. Sustainability. 2019;12(1):1-16. doi:10.3390/su12010333

37. Ajzen I. The theory of planned behavior. Organ Behav Hum Decis Process. 1991;50(2):179-211. doi:10.1016/0749-5978(91)90020-T

38. Rocha CM, Fleury FA. Attendance of Brazilian soccer games: the role of constraints and team identification. Eur Sport Manag $Q$ 2017;17:485-505. doi:10.1080/16184742.2017.1306871

39. Funk DC, Alexandris K, McDonald H. Sport Consumer Behaviour: Marketing Strategies. Routledge; 2016.

40. Kim Y, Magnusen M, Kim M, et al. Meta-analytic review of sport consumption: factors affecting attendance to sporting events. Sport Mark Q. 2019;28(3):117-134. doi:10.32731/SMQ.283.092019.01

41. Funk DC, Mahony DF, Ridinger LL. Characterizing consumer motivation as individual difference factors: augmenting sport interest inventory (SII) to explain level of spectator support. Sport Mark $Q$. 2002;11(1):33-43.

42. Heng SP, Zhao HF, Wang MH. In-game social interaction and gaming disorder: a perspective from online social capital. Front Psychiatry. 2021;11:468115. doi:10.3389/fpsyt.2020.468115

43. Penner LA, Dovidio JF, Piliavin JA, Schroeder DA. Prosocial behavior: multilevel perspectives. Аnnu Rev Psychol. 2005;56:365-392. doi:10.1146/annurev.psych.56.091103.070141

44. Yue Z, Yang JZ. Compassionate goals, prosocial emotions, and prosocial behaviours during the COVID-19 pandemic. J Community Appl Soc Psychol. 2021;18:215.
45. Eitle D, Swinford S, Klonsinski A. Male high school sport participation and intimate partner violence perpetration in adulthood. Sociol Sport J. 2021;38(2):188-195. doi:10.1123/ssj.2019-0185

46. Jang W, Wu LW, Wen J. Understanding the effects of different types of meaningful sports consumption on sports consumers' emotions, motivations, and behavioral intentions. Sport Manag Rev. 2021;24 (1):46-68. doi:10.1016/j.smr.2020.07.002

47. Killen M, Verkuyten M. The importance of social-cognitive development and the developmental context for group dynamics. Group Processes Intergroup Relat. 2017;20(5):707-718. doi:10.1177/ 1368430217711771

48. Bruner MW, Boardley ID, Côté J. Social identity and prosocial and antisocial behavior in youth sport. Psychol Sport Exerc. 2014;15 (1):56-64. doi:10.1016/j.psychsport.2013.09.003

49. Graupensperger SA, Jensen CJ, Evans MB. A meta-analytic review of studies using the Prosocial and Antisocial Behavior in Sport Scale: associations among intergroup moral behaviors. Sport, Exerc, Perform Psychol. 2018;7(2):186-204.

50. Heinberg M, Liu Y, Huang X, Eisingerich AB. A bad job of doing good: does corporate transparency on a country and company level moderate corporate social responsibility effectiveness? J Int Mark. 2021;29(2):45-61. doi:10.1177/1069031X20981870

51. Lee SH. Effects of retailers' corporate social responsibility on retailer equity and consumer usage intention. Sustainability. 2021;13 (6):3080. doi:10.3390/su13063080

52. Sánchez-Sáez JA, Segado F, Calabuig-Moreno F, Gallardo Guerrero AM. Measuring residents' perceptions of corporate social responsibility at small- and medium-sized sports events. Int J Environ Res Public Health. 2020;17(23):8798. doi:10.3390/ijerph17238798

53. Inoue Y, Funk DC, McDonald H. Predicting behavioral loyalty through corporate social responsibility: the mediating role of involvement and commitment. J Bus Res. 2017;75:46-56. doi:10.1016/j. jbusres.2017.02.005

54. Chen CY, Lin HS. Social entrepreneurship in professional sports: antecedents and outcomes from the consumer perspective. Sustainability. 2021;13(3):1045. doi:10.3390/su13031045

55. Yu CL. The role of CSR in sport consumption decision-making. Mark Intell Plan. 2021;39(1):17-32. doi:10.1108/MIP-02-2020-0060

56. Khan A, Chen LR, Hung CY. The role of corporate social responsibility in supporting second-order social capital and sustainable innovation ambidexterity. Sustainability. 2021;13(13):1-15. doi:10.3390/ su132112160

57. Filo K, Funk DC, O'Brien D. It's really not about the bike: exploring attraction and attachment to the events of the Lance Armstrong Foundation. J Sport Manag. 2008;22(5):501-525. doi:10.1123/ jsm.22.5.501

58. Filo K, Funk DC, O'Brien D. The meaning behind attachment: exploring camaraderie, cause, and competency at a charity sport event. $J$ Sport Manag. 2009;23(3):361-387. doi:10.1123/ jsm.23.3.361

59. Filo K, Funk DC, O'Brien D. The antecedents and outcomes of attachment and sponsor image within charity sport events. $J$ Sport Manag. 2010;24(6):623-648. doi:10.1123/jsm.24.6.623

60. Bhattacharya CB, Korschun D, Sen S. Strengthening stakeholdercompany relationships through mutually beneficial corporate social responsibility initiatives. $J$ Bus Ethics. 2009;85(2):257-272. doi:10.1007/s10551-008-9730-3

61. Thornton MA, Rupp DE. The joint effects of justice climate, group moral identity, and corporate social responsibility on the prosocial and deviant behaviors of groups. J Bus Ethics. 2016;137:677-697. doi:10.1007/s10551-015-2748-4

62. Hur W-M, Moon T-W, Choi W-H. When are internal and external corporate social responsibility initiatives amplified? Employee engagement in corporate social responsibility initiatives on prosocial and proactive behaviors. Corp Soc Responsib Environ Manag. 2019;26(4):849-858. doi:10.1002/csr.1725 
63. Shin I, Hur W-M. How are service employees' perceptions of corporate social responsibility related to their performance? Prosocial motivation and emotional labor as underlying mechanisms. Corp Soc Responsib Environ Manag. 2020;27(6):2867-2878. doi:10.10 02/csr.2008

64. Tao W, Song B, Ferguson MA, et al. Employees' prosocial behavioral intentions through empowerment in CSR decision-making. Pub Relat Rev. 2018;44(5):667-680. doi:10.1016/j.pubrev.2018.07.002

65. Foxton F, Jones R. Social Capital Indicators Review. Office for National Statistics in UK; 2011.

66. Grootaert C, Narayan D, Jones VN, et al. Measuring social capital: an integrated questionnaire. World Bank Working Paper; 2004. 18. Available from: https://openknowledge.worldbank.org/handle/10986/ 15033. Accessed 2 September, 2021.

67. Zhang Q, Yang Y, Zhang GL. Influence of life meaning on subjective well-being of older people: serial multiple mediation of exercise identification and amount of exercise. Front Public Health. 2021;9:867.

68. Zsila A, Orosz G, McCutcheon LE, Demetrovics Z. Individual differences in the association between celebrity worship and subjective well-being: the moderating role of gender and age. Front Psychol. 2021;2:651067. doi:10.3389/fpsyg.2021.651067

69. Kim J, Kim M. Spectator e-sport and well-being through live streaming services. Tech Soc. 2020;63(C):101401. doi:10.1016/j. techsoc.2020.101401

70. Inoue Y, Wann DL, Lock D, Sato M, Moore C, Funk D. Enhancing older adults' sense of belonging and subjective well-being through sport game attendance, team identification, and emotional support. $J$ Aging Health. 2020;32(7-8):530-542. doi:10.1177/089826 4319835654

71. Inoue Y, Lock D, Sato M, Funk D. Psychological processes connecting team identification and social well-being for middle-aged and older adults: moderated mediation of subjective and objective on-field performance. Sport Manag Rev. 2021;1-27. doi:10.1080/ 14413523.2021.1917246

72. Hommerich C, Tiefenbach T. Analyzing the relationship between social capital and subjective well-being: the mediating role of social affiliation. J Happiness Stud. 2018;19(4):1091-1114. doi:10.1007/ s10902-017-9859-9

73. Portela M, Neira I, Salinas-Jiménez M. Social capital and subjective wellbeing in Europe: a new approach on social capital. Soc Indic Res. 2013;114(2):493-511. doi:10.1007/s11205-012-0158-x

74. Hwang L, Ng J, Vaithilingam S. Social capital and subjective well-being: the mediating role of social networking sites. First Monday. 2019;24(10):7.

75. Sun YN, Lin YH. Using sports participation as a lifeline to promote psychological wellbeing and happiness among older individuals in China: mediating role of social capital dimensions. Revista de Psicología del Deporte. 2021;30(2):487.
76. You S, Lee J, Lee Y. Relationships between gratitude, social support, and prosocial and problem behaviors. Curr Psychol. 2020. doi:10.1007/s12144-020-00775-4

77. Alkozei A, Smith R, Killgore WDS. Gratitude and subjective wellbeing: a proposal of two causal frameworks. J Happiness Stud. 2018;19(5):1519-1542. doi:10.1007/s10902-017-9870-1

78. Tilley E, Strnadova I, Danker J, et al. The impact of self-advocacy organizations on the subjective well-being of people with intellectual disabilities: a systematic review of the literature. $J$ Appl Res Intellect Disabil. 2020;33(6):1151-1165. doi:10.1111/jar.12752

79. Zheng X, Xie F, Ding L. Mediating role of self-concordance on the relationship between Internet altruistic behaviour and subjective wellbeing. J Pac Rim Psychol. 2018;12(e1):1-7. doi:10.1017/ prp.2017.14

80. O'Cass A, Griffin D. Eliciting positive social change: marketing's capacity to drive prosocial behaviours. Mark Intell Plan. 2015;33 (5):826-843. doi:10.1108/MIP-02-2014-0027

81. Batson CD, Powell AA. Altruism and prosocial behavior. In: Millon T, Lerner MJ, editors. Handbook of Psychology: Personality and Social Psychology. John Wiley \& Sons, Inc; 2003.

82. Barry CM, Wentzel KR. Friend influence on prosocial behavior: the role of motivational factors and friendship characteristics. Dev Psychol. 2006;42(1):153-163. doi:10.1037/0012-1649.42.1.153

83. Number of spectators in CPBL; 2021. Available from: https://zxc22. idv.tw/by total2.asp?clickflag=999. Accessed 7 November, 2021.

84. Woolcock M, Narayan D. Social capital: implications for development theory, research, and policy. World Bank Res Obs. 2000;15 (2):225-249. doi:10.1093/wbro/15.2.225

85. Lichtenstein DR, Drumwright ME, Braig BM. The effect of corporate social responsibility on customer donations to corporate-supported nonprofits. $J$ Mark. 2004;68(4):16-32. doi:10.1509/jmkg.68.4.1 6.42726

86. Baumsteiger R, Siegel JT. Measuring prosociality: the development of a prosocial behavioral intentions scale. J Pers Assess. 2018;101 (3): $1-10$.

87. Kline RB. Principles and Practice of Structural Equation Modeling. 5th ed. The Guilford Press; 2011:3-427.

88. Nunnally JC, Bernstein IH. The assessment of reliability. Psychom Theory. 1994;3:248-292.

89. Podsakoff PM, Mackenzie SB, Lee J-Y, et al. Common method biases in behavioral research: a critical review of the literature and recommended remedies. J Appl Psychol. 2003;88(5):879-903. doi:10.1037/0021-9010.88.5.879

90. Kline RB. Principles and Practice of Structural Equation Modeling. New York: The Guiford Press; 1998.

91. Hair JF, Black WC, Babin BJ, et al. Multivariate Data Analysis. 7th. Andover, Hampshire: Cengage; 2019.
Psychology Research and Behavior Management

\section{Publish your work in this journal}

Psychology Research and Behavior Management is an international, peer-reviewed, open access journal focusing on the science of psychology and its application in behavior management to develop improved outcomes in the clinical, educational, sports and business arenas. Specific topics covered in the journal include: Neuroscience, memory and decision making; Behavior modification and management; Clinical applications; Business and sports performance management; Socia and developmental studies; Animal studies. The manuscript management system is completely online and includes a very quick and fair peer-review system, which is all easy to use. Visit http://www. dovepress.com/testimonials.php to read real quotes from published authors. 